\title{
From the Editor's Desk
}

\author{
Janice Honeyman-Buck
}

Published online: 7 September 2011

(C) Society for Imaging Informatics in Medicine 2011

We have had an exciting few months with the Journal of Digital Imaging.

I am so pleased to report that we are in a growth phase with the Journal of Digital Imaging (JDI). We have grown to larger, more frequent issues with very high-quality content. In an attempt to move articles from online-first to the print issues, we have been publishing larger issues, and by the beginning of 2012, we will have and will attempt to continue to have only a two to three issue backlog which means completed articles will be published in print from 4 to 6 months after online-first.

To make JDI more accessible to its readers, the full-text content is now also available in PubMed Central (PMC). PMC is a free full-text archive of biomedical and life sciences journal literature at the US National Institutes of Health's National Library of Medicine (NIH/NLM). JDI articles are made available freely accessible in PMC upon 1 year of issue publication and content is available dating back to volume 16 (2003). The greater availability of JDI content made through PMC provides various benefits and potential advantages. Authors enjoy the benefit of further dissemination of their work, and in turn, the journal receives increased visibility and exposure. The major advantage of expanding the visibility of the journal is the potential gain of article downloads and citations. Since JDI was made available in PMC in March 2011, there has been more than 12,000 full-text article downloads on PMC alone! Please visit $J D I$ in PMC at http://www.ncbi.nlm.nih. gov/pmc/journals/1429/. Issues of $J D I$ published prior to our on-line presence were digitized and are available at SpringerLink for everyone. To get to JDI on SpringerLink, either link through from www.siimweb.org/jdi or go to www.springerlink.com and search for the Journal of Digital Imaging.

We received the news that our standard impact factor for 2010 increased to 1.413 from the 2009 standard impact factor of 0.956 . We now rank 69 out of 111 in Radiology, Nuclear Medicine, and Medical Imaging Journals in 2010, up from our ranking of 80 out of 104 in Radiology, Nuclear Medicine, and Medical Imaging Journals in 2009. Our 5year impact factor for 2010 increased to 1.427 from the 20095 -year impact factor of 1.192.

We thank all our authors, associate editors, reviewers, and SIIM editorial staff for their support for the Journal of Digital Imaging and look forward to continuing to grow in size and stature.
J. Honeyman-Buck $(\bowtie)$

508 Bramble Fern Ave,

DeLand, FL 32720, USA

e-mail: jhoneyman@siimweb.org 